\title{
Bimbenet, É. Après Merleau-Ponty. Études sur la fécondité d'une pensée. Paris: Vrin, 2011
}

\section{0 pensamento de Merleau-Ponty e a insistência da ambiguidade}

Silvana de Souza Ramos (Pós-doutorando Universidade de São Paulo bolsista Fapesp, São Paulo, São Paulo, Brasil.)

ramos_si@yahoo.com.br

A presente resenha analisa o livro de Étienne Bimbenet - Après Merleau-Ponty. Études sur la fécondité d'une pensée -, onde o autor considera a obra do fenomenólogo francês, não como objeto de exegese, mas como uma matriz filosófica ainda fecunda. A filosofia de Merleau-Ponty exige uma nova idéia de razão, enraizada no sensível. Consequentemente, ela permite um diálogo fértil com o saber positivo, sem que isso signifique uma redução do homem às determinações empíricas. Pelo contrário, o homem é abordado como uma figura ambígua que oscila entre a inerência vital e a intenção racional. 0 objetivo de Bimbenet - realizado mediante a confrontação de Merleau-Ponty com outros autores os quais tacitamente continuam a empregar tal abordagem - é trazer à luz a herança merleau-pontiana e, através disso, mostrar a relevância e a necessidade dessa perspectiva filosófica.

0 recente livro de Étienne Bimbenet - Après Merleau-Ponty. Études sur la fécondité d'une pensée - aborda a obra do fenomenólogo francês no intuito de mostrar que se trata de uma matriz filosófica ainda fecunda. Segundo Bimbenet, a filosofia de Merleau-Ponty tem um caráter programático, quer dizer, ela descentraliza a subjetividade transcendental em direção aos poderes do corpo próprio, exigindo uma nova idéia de razão, simultaneamente 
enraizada no sensível e aberta à universalidade do sentido. Consequentemente, ela permite um diálogo fértil com o saber positivo, sem que isso signifique uma redução do homem às determinações empíricas. 0 objetivo de Bimbenet é trazer à luz a potência dessa abordagem antropológica e, através disso, mostrar a relevância e a necessidade atual dessa perspectiva de pesquisa.

Nas últimas décadas, o interesse pela obra de Merleau-Ponty tem sido constantemente revigorado, o que pode ser atestado pela quantidade de publicações a ela dedicadas. Pouco mais de meio século após a morte do filósofo, em consonância com o diagnóstico de Bimbenet, é possível dizer que seu pensamento se faz presente, embora o desafio de decifrar o alcance de sua obra ainda se esboce sob a forma de uma tarefa a ser realizada. Há, por um lado, indícios bastante claros de que a vinda a público dos estudos de Renaud Barbaras fez com que Merleau-Ponty conquistasse um terreno próprio, uma vez que lançou um novo olhar sobre a ontologia indireta, pautada pela recusa de uma fenomenologia idealista, e, portanto, avessa ao passo em direção à constituição de um mundo cujo sentido dependeria de atos da consciência ${ }^{1}$. Por outro lado, a herança merleau-pontiana parece pulsar em desdobramentos da filosofia e das ciências humanas, sem que o reconhecimento da paternidade de algumas ideias se dê de maneira clara e imediata. Não se trata simplesmente de usurpação ou de má-fé, pois, se Merleau-Ponty criou uma fala que continua a produzir ecos sem necessitar da justificava acadêmica da citação, isso se deve mais à potência de seu filosofar do que ao descaso ou ao pudor daqueles que o retomam sem avisar.

Em Après Merleau-Ponty, Étienne Bimbenet assume a tarefa de compreender essa herança inconfessa - poderíamos dizer: essa tradição que se avoluma no horizonte aberto pela filosofia de Merleau-Ponty. Deve-se salientar que essa não é a primeira vez que o autor se debruça sobre a obra do filósofo, pois, dentre as inúmeras contribuições no que tange ao entendimento e à proliferação do pensamento merleau-pontiano, destaca-se a importância do livro publicado em 2004 - Nature et Humanité. Le problème anthropoplogique dans l'ouvre de Merleau-Ponty - onde já é realizada uma análise precisa e original da fenomenologia praticada por Merleau-Ponty, na medida em que dá lugar a uma interessante abordagem do problema antropológico. Segundo Bimbenet, mesmo depois do anúncio da iminente morte do homem - cujo rosto desenhado na areia precisaria apenas de uma leve onda para dissipar-se -, a voz de Merleau-Ponty ressoa como um convite para pensar o enigma de nossa humanidade - ao mesmo tempo enraizada no solo biológico do corpo e aberta ao possível e à história; lugar ambíguo onde natureza e cultura disputam terreno sem que haja no horizonte a exigência de uma síntese definitiva, a qual suprimiria uma dessas dimensões. 
Dando continuidade à pesquisa empreendida no livro anterior, o propósito de Après Merleau-Ponty pode ser pressentido nas pistas fornecidas por seu título. 0 problema antropológico ainda reside em seu cerne, embora seja preciso mais uma vez salientar que não se trata apenas de oferecer uma análise interna do discurso merleau-pontiano, trabatho realizado pelo livro precedente. Ao se referir a um depois, Bimbenet traça um marco inicial na história das idéias para dar visibilidade ao papel de Merleau-Ponty - isto é, à sua fecundidade - no que tange aos desenvolvimentos recentes tanto da filosofia quanto das ciências humanas. Dissecada através da confrontação entre Merleau-Ponty e seus possíveis herdeiros (alguns deles são, na verdade, contemporâneos do filósofo, ainda que pensem $a$ partir da mesma matriz investigativa) - desde a provocativa presença de Foucault, passando por Derrida, Habermas, Lévi-Strauss, Ric?ur, Bachelard, Bourdieu e MacDowell, além de discussões acerca da psiquiatria e da neurobiologia - essa fecundidade vai sendo desvelada em cada capítulo do livro, fornecendo ao leitor um complexo panorama do pensamento contemporâneo, no interior do qual a questão sobre o homem continua a insistir.

Esse procedimento é por si só a retomada do método de leitura formulado e praticado por Merleau-Ponty: há aqui um tournant segundo o qual o alcance da obra é decifrado pelo arcabouço de interpretação que ela própria fornece. Ora, do ponto de vista de MerleauPonty, a fecundidade de um autor pode ser medida não só pelo que ele efetivamente diz quer dizer, por aquilo que se encontra explicitamente apresentado ou literalmente visível na letra do texto - mas também por aquilo que ele incita a pensar (embora não tenha efetivamente pensado), isto é, pelo invisivel que dá profundidade à sua obra permitindo que ela seja retomada de forma criativa; ou seja, não apenas para que seja mimetizada, mas, principalmente, para que o horizonte conceitual aberto por ela continue a engendrar diferentes visões compreensivas do mundo.

Decerto, segundo a perspectiva merleau-pontiana, a instituição de uma nova fala - ou de um novo horizonte teórico - não depende de uma decisão porque acontece no interior de um diálogo com o passado, em relação ao qual se estabelece um jogo complexo entre continuidade e produção da diferença. Por isso, muitas vezes, descobrimos em autores posteriores o eco de uma voz antiga desdobrada em direções inesperadas.

Essa potência póstuma do pensar - essa invisibilidade pulsante em toda grande obra de cultura, capaz de vir à figura pelo trabalho daqueles que são formados por ela exige a compreensão da noção de tradição e de leitura, às quais Merleau-Ponty forneceu uma formulação e um sentido precisos. Segundo o filósofo, é preciso considerar que uma tradição - ou seja, um conjunto de significações disponíveis ao pensamento atual - envolve esquecimento, na medida em que se trata de um saber instituído ou sedimentado. Em outras palavras, a disponibilidade de certas ideias esconde seu caráter 
original, isto é, o fato de que um dia elas foram criações. Disponíveis posteriormente sob a forma de um saber instituído ou de uma tradição, elas configuram o solo a partir do qual começamos a pensar. Porém, se tais ideias dão vazão a um estilo de pensamento, elas não impedem, contudo, desdobramentos imprevisíveis, possibilitando, assim, o surgimento de novas criações. Daí o sentido outorgado por Merleau-Ponty ao exercício da leitura: ler não é apenas respeitar literalmente um texto, mas permitir-se o trabalho da diferença, de tal modo que o devir do pensamento não seja interrompido por uma fidelidade estéril ${ }^{2}$.

Sendo assim, tendo em vista a perspectiva de uma retomada do pensamento de Merleau-Ponty - buscando ao mesmo tempo mostrar o que a partir dele sedimentou uma tradição, e o que ainda demanda o exercício atual do pensar -, o livro de Bimbenet fornece uma moldura segundo a qual poderíamos empreender uma leitura fecunda. Por um lado, exige que reconheçamos o caráter programático dessa obra: seja nos conceitos que forja, seja no método que emprega, há ali um projeto, isto é, um anúncio direcionado ao futuro sob a forma da promessa. Quer dizer, a despeito das circunstâncias de sua morte prematura em 1961 - a qual efetuou um corte abrupto no desenvolvimento de sua obra, no momento em que uma nova configuração conceitual estava prestes a florescer - pode-se reconhecer nos ditos de Merleau-Ponty uma explícita demanda por continuidade. Por outro lado, há que se reconhecer a efetividade desse programa no interior do pensamento contemporâneo. Não se trata, portanto, de reavivar uma obra condenada ao silêncio ou de retomar algo que corria risco de extinção. Pelo contrário, uma vez que Merleau-Ponty produziu uma tradição, visitá-lo significa retornar a uma das origens do pensamento atual, desfazendo assim o esquecimento que a envolve.

Desvela-se assim o duplo sentido do título do livro: Après Merleau-Ponty aponta para aquilo que foi pensado a partir de Merleau-Ponty, e em consonância (nem sempre evidente) com seu programa filosófico, mas assinala também a vitalidade atual dessa proposta. Neste ponto, Bimbenet se mostra enfático, pois afirma ser necessário pensar depois de Merleau-Ponty uma vez que a "ambiguidade é um quadro teórico dificilmente contestável, em sua generalidade; é doravante uma paisagem quase obrigatória de pesquisa, mas no interior da qual justamente todo o trabalho resta a fazer" (Bimbenet, 2011, pp. 238-9, grifo nosso). 0 objetivo do livro é, pois, avançar nessa direção, explorando a insistência da questão sobre o homem e a exigência que ela implica de um diálogo entre a filosofia e o saber positivo. Sendo assim, ao colocar Merleau-Ponty na posição de um marco histórico no que diz respeito à investigação sobre o sentido de ser da humanidade - defendendo que seu caráter ambíguo continua a ser um horizonte inexorável para qualquer estudo antropológico -, Bimbenet se interessa exatamente pelo 


\section{0}

jogo entre continuidade e diferença. 0 autor pretende mostrar que a tradição merleaupontiana tece secretamente diferentes discursos sobre o homem, os quais são engendrados a partir das mesmas prerrogativas gerais.

Mas o que significa a ambiguidade atestada por Merleau-Ponty? Por que ela necessariamente nos concerne? Como podemos escapar do diagnóstico de Foucault, apresentado em Les mots et les choses, segundo o qual o caráter vacilante do duplo empírico transcendental - na medida em que engendra um discurso misto - estaria fadado a se desfazer, o que justificaria a anúncio da morte do homem?

Sabemos que para Foucault o homem é uma figura ambígua que as ciências humanas constituem como um conjunto de positividades empíricas diversas, mas ao qual a filosofia dá o papel de fundamento, garantindo, assim, a possibilidade da própria ciência ${ }^{3}$. Em outras palavras, o homem é ao mesmo tempo objeto empírico do saber e sujeito transcendental desse mesmo saber. Nestes termos, trata-se de uma perspectiva insustentável: entre um e outro, há que se escolher. Por isso, não é de espantar que o movimento arqueológico possibilitado por essa abordagem - uma vez que enfraquece a subjetividade transcendental por meio do desvelamento de sua base corporal, linguística e social - na verdade prepare o movimento de liberação das ciências humanas da tutela filosófica. Lido sob essa perspectiva, o humanismo de Merleau-Ponty representaria um momento transitório, sucedido por um positivismo feliz.

Bimbenet não se conforma, porém, com esse diagnóstico, e convida o leitor a visitar o cenário da morte do homem e sua posteridade, enfatizando momentos em que o próprio Foucault pode ser surpreendido numa perspectiva filosófica contrária ao impiedoso anúncio fúnebre feito em 1966. Mais precisamente, trata-se de reconhecer que a crítica de Foucault visa a razão e o homem na medida em que se tornaram ídolos, isto é, obstáculos para o exercício do pensamento e da liberdade. Sendo assim, "a morte do homem é um gesto 'crítico', que desloca os limites do pensamento e the abre um novo domínio de exploração" (Bimbenet, 2011, p. 19). Nestes termos, pode-se, a partir desse gesto, alargar a razão, o que propiciaria a retomada do projeto emancipador moderno, anunciado pela Aufklärung.

É claro que essa retomada tem um teor peculiar, uma vez que opera sob o signo da cultura do limite, configurando, assim, um èthos filosófico mais próximo de Heidegger (e de Hegel) do que de Kant. Noutras palavras, o projeto emancipador não declara insuperáveis os limites reconhecidos pela razão, ao contrário, defende uma atitude filosófica segundo a qual a travessia do limite aparece como uma exigência. Daí a necessidade foucaultiana de destruir os ídolos da razão e a preocupação merleau-pontiana em descrever o advento contingente do sentido, quando a razão extrapola os impasses que a aprisionam dentro de um 
quadro ontológico insuficiente. Nos dois casos, um pensamento fiel a si mesmo deve estar aberto ao que ainda não sabe, resolvendo-se na forma da tentativa e do ensaio.

Ora, a passagem por Foucault no primeiro capítulo do livro abre um caminho para a investigação da figura do excesso na filosofia de Merleau-Ponty. Contudo, essa aproximação entre os filósofos só se realiza porque Bimbenet disseca o programa antropológico merleau-pontiano, no intuito de nele encontrar uma espécie de esquema geral, aplicável às diversas dimensões da experiência, de tal modo que seja possível estabelecer o confronto entre Merleau-Ponty e outros autores. Mas, afinal, quem é o homem merleau-pontiano desvelado pelo funcionamento concreto da percepção? Por que a estrutura da percepção pode fornecer uma "paisagem geral de pesquisa", tal como defende Bimbenet? Segundo Merleau-Ponty, a percepção, uma vez que não pode sobrevoar o objeto (isto é, não pode possuí-lo inteiramente), visa necessariamente algo além do imediatamente dado, abrindose, portanto, à totalidade. Noutras palavras, perceber não é apenas apreender a figura diante de nós, mas remeter-se às visões - tanto minhas, quanto de meus congêneres - que dela possam ser produzidas. Isso significa que, embora o primeiro contato com a coisa externa seja vital - isto é, engendrado por um corpo situado no mundo -, esse contato não seria humano se não fosse capaz de se abrir ao possível, quer dizer, se a teleologia da razão não o invadisse, fazendo-o visar de maneira presuntiva tanto a totalidade da coisa, quanto a comunidade de videntes que poderiam percebê-la.

Nestes termos, o caráter originário da percepção mostra que o contato com o mundo exterior está sempre submetido a uma teleologia sem conceitos, pois se modula pela ambição simultânea do universal e do comum, operante em toda e qualquer visão parcial e privada. Quer dizer, desde a relação originária entre sujeito e mundo - isto é, desde a percepção mais elementar - o que se nota é, de um lado, a concretude de um processo que só pode se realizar porque o corpo próprio enraíza a experiência no mundo; de outro lado, porém, devemos considerar que esse enraizamento se expande para além do contato imediato, por conta da teleologia da razão. Descrito em sua estrutura geral, a abertura do homem ao mundo apresenta-o como um ser que oscila entre a inerência vital e a intenção racional, o que nos obriga a observar o caráter essencialmente excessivo da racionalidade, pois, apesar de fincada na experiência concreta, ela extrapola o imediato, para dar origem à teleologia do sentido. Esse esquema geral apresentado por Bimbenet - o esquema fecundo da ambiguidade, desenhado a partir da percepção e desdobrado em diferentes âmbitos da experiência - é o que permite, enfim, a confrontação entre Merleau-Ponty e outros autores, apresentados como herdeiros do fenomenólogo francês.

0 terreno mais evidente a ser explorado é o da antropologia. Assim, Bimbenet argumenta que, embora não tenha acontecido um extenso diálogo entre Merleau-Ponty e Lévi- 


\section{2}

Strauss, por exemplo, ambos disseram algo novo e de comum sobre o ser humano. 0 filósofo e o antropólogo concorrem para abordagens semelhantes seja da relação entre natureza e cultura, seja da infância, seja, ainda, do conceito de simbólico. Pois, para os dois autores, a cultura não é uma esfera separada da natureza, ao contrário, ela é uma forma de viver - a qual se realiza pela integração do biológico em novos tipos de comportamento, os quais extrapolam o âmbito da natureza, sem, contudo, suprimi-la. Assim, para Lévi-Strauss, quando surge a interdição do incesto, acontece a passagem do fato natural da consanguinidade ao fato cultural da aliança. Nos termos de Merleau-Ponty, eventos como este mostrariam que o comportamento humano se enraíza no biológico, fornecendolhe, porém, um sentido inédito. Consequentemente, para os dois autores, a cultura é uma transformação que acontece no interior do comportamento biológico, dando lugar ao simbólico. Porém, realizada a passagem à cultura, o comportamento simbólico passa a preponderar (a não ser em casos patológicos, os quais implicam a desestruturação do comportamento, reduzindo-o à normatividade vital). É por isso que para ambos a infância humana deve ser concebida como o lugar de exibição do arcaico - não no sentido histórico, mas estrutural, pois ela traz em si a forma da sociabilidade, antecipando o que será realizado na vida adulta. Noutras palavras, a infância não é propriamente natureza, mas prefiguração da cultura. Por fim, em relação ao simbólico - num movimento análogo ao que desvenda o sentido da infância -, Lévi-Strauss busca sua origem arcaica, fazendo do primitivo a expressão do início, isto é, a aparição de uma organização da sociabilidade e da razão, prenhe de possibilidades e, portanto, pouco adaptada aos fins perseguidos.

Observe-se que a consideração do excesso da razão atesta que sua ineficácia originária - seja no caso particular da infância, seja no caso das sociedades primitivas - deve ser explicada positivamente, pois ela não é o signo de uma falta ou de uma falha do comportamento; ao contrário, ela indica a abertura a diversas possibilidades de realização da vida afetiva e social. Merleau-Ponty, é claro, tem uma concepção semelhante, uma vez que, especialmente em sua obra final, o filósofo fala de um simbolismo originário - caracterizado pela indivisão e pela empatia generalizada entre os corpos -, sem o quê seria impossível o desenvolvimento posterior da afetividade e da sociabilidade.

A figura merleau-pontiana do excesso pode ser observada também nos estudos ulteriores sobre a linguagem. Por isso, Bimbenet retoma o esquema geral da ambiguidade e se aventura pela teoria do agir comunicativo de Habermas para mostrar que, segundo o filósofo alemão, o ato de falar é essencialmente contrafactual, uma vez que nega as condições dadas em proveito de um horizonte de direito. Quer dizer, a fala descrita por Habermas assim como a percepção em Merleau-Ponty - presume que somos uma comunidade de seres racionais (capazes, portanto, de compreender uns aos outros), os quais sempre se referem 
a um mesmo mundo. Essa dupla presunção - diria Merleau-Ponty - é peculiar ao comportamento humano, pois este só se realiza sob a vigência do excesso inerente a qualquer abordagem racional do mundo, posto que visa um universal, passivel de ser partilhado entre os homens.

Podemos perceber, então, a relevância da ideia de excesso na abordagem merleaupontiana do homem. Decerto, o excesso constitutivo da razão configura aquilo que necessariamente escapa ao fato, isto é, ao dado imediato, mas que, entretanto, está presente em todo e qualquer ato humano, dando-lhe um sentido teleológico. Deste modo, já que a humanidade se define por este jogo entre dado e visado - entre fato e direito - Bimbenet assevera que a crítica dirigida por Derrida a Foucault poderia ter sido perfeitamente elaborada sob inspiração merleau-pontiana ${ }^{4}$. Afinal, como expandir a razão? Através da conquista de um terreno exterior ao advento da racionalidade - o irracional, expresso na loucura, por exemplo? Seria o caso de persistir na tentativa contraditória de dar voz ao silêncio? Não propriamente, já que o irracional - isto é, a presunção da totalidade e da comunidade operante na experiência humana - pertence originariamente à razão. Por isso, paradoxalmente, a conquista de novos terrenos não acontece sem o movimento de retorno ao arcaico: é preciso, pois, mostrar que sem excesso não haveria razão, tampouco humanidade - de tal forma que o movimento de retorno configura a reconquista do poder simbólico da razão. Daí o papel da apropriação das descobertas científicas, na medida em que, ao invés de reduzir o homem ao empírico, elas abrem a possibilidade de rememorar e de compreender o advento contingente da humanidade.

É por isso que o esquema geral da ambiguidade pode ser ainda vislumbrado nos estudos acerca da imaginação e do Belo, permitindo uma aproximação entre Merleau-Ponty e Bachelard, pois "ambos partilham uma mesma sensibilidade, a qual poder-se-ia dizer dinâmica. Imaginar, ver, pensar são (...) atos fundamentalmente criadores" (Bimbenet, 2011, p. 107), porquanto a admiração diante da beleza do mundo não pode ser reduzida à passividade, uma vez que recria o mundo, desvendando-lhe perfis inéditos os quais renovam a experiência, ampliando seus horizontes. Mas não só isso. A experiência transbordante da razão - o processo segundo o qual os comportamentos são envolvidos e transformados, dando nascimento ao ser excessivo do homem - aparece, ainda, na sociologia de Bourdieu, na psiquiatria existencial, na neurobiologia, entre outros. Assim, os estudos dedicados às diferentes dimensões da experiência humana - tomadas sob a ótica da filosofia ou das ciências -, reforçam e desdobram o programa de expansão da razão (compreendido como um retorno à sua origem excessiva, visando a reconquista de seu movimento expansivo), de modo que a leitura de Bimbenet realiza o intento de colocar Merleau-Ponty na posição de fundador de uma tradição ainda hoje fecunda. 


\section{4}

Ora, o traço mais original do livro é o fato de ela inverter o sentido da investigação merleau-pontiana: ao invés de se perguntar pelo corpo do espírito (isto é, ao invés de fazer um caminho descendente em direção ao passado corporal da consciência), ele tenta compreender como a humanidade foi possível, ou, em outras palavras, como a animalidade pôde se tornar capaz de percepção e de linguagem, trazendo consequentemente o espírito ao mundo (assumindo, portanto, uma direção investigativa ascendente). É por isso que suas análises privilegiam a apropriação filosófica de certas descobertas surgidas no campo das ciências humanas - tais como o funcionamento da fala ou, ainda a proibição do incesto - as quais possibilitam pensar o advento da humanidade e da cultura, sem que isso exija 0 abandono da perspectiva da ambiguidade.

Sendo assim, a investigação sobre o homem se formula como problema e dispensa, portanto, qualquer procedimento dogmático. Trata-se de confrontar reiteradamente o enigma do surgimento do homem, reposto por cada um de seus comportamentos. Por isso, devemos insistir na tentativa de compreender o fundo arcaico da razão, sem abrir mão daquilo sem o quê, no limite, não haveria humanidade, isto é, a teleologia do sentido. Ora, desde o início do livro, Bimbenet deixa claro que não se trata de um programa solitário, do qual Merleau-Ponty seria o único ator: pelo contrário, a França dos anos 1930 é marcada pela decisão - tomada segundo uma tonalidade hegeliana - de alargar a razão nela integrando o que as ciências humanas estavam prestes a descobrir. Porém, ao fornecer uma espécie de esquema geral segundo o qual é possível dar continuidade a essa aventura antropológica - ao fincar, portanto, um marco original na história do pensamento contemporâneo, através da explicitação do caráter ambíguo do homem -, a obra de Merleau-Ponty traz à luz o quiasma entre natureza e cultura, o qual pôde ser explorado mediante diversas figuras. Em suma, sob a pena de Merleau-Ponty, o programa de expansão da racionalidade ganha um contorno preciso, pois exige considerar concretamente duas dimensões irreconciliáveis - a vida e o espírito - as quais permitiram o advento do homem, inaugurando uma ordem de sentido inédita.

Entretanto, é preciso observar que essa trajetória, recheada de aproximações, por vezes inusitadas, só foi possível porque Bimbenet realizou um esvaziamento do programa merleau-pontiano, em proveito da fecundidade de seu esquema geral. Sendo assim, a única ressalva que poderia ser feita ao seu trabalho é em relação à desistência que ele parece exigir. Trata-se, em suma, de dar menos atenção ao conteúdo da filosofia merleau-pontina, para aproveitar ao máximo a fecundidade do esquema da ambiguidade, o que obriga Bimbenet a desconsiderar as especificidades encontradas na filosofia de Merleau-Ponty, as quais poderiam barrar certas filiações. Talvez por isso o autor praticamente não toque no problema referente à divisão da obra de Merleau-Ponty em diferentes fases. Que dizer das 
mudanças teóricas ocorridas a partir dos anos 1950? Será que elas sustentam o mesmo esquema antropológico? Que significa "inerência vital" a partir do momento em que uma nova teoria da vida se desenha no pensamento de Merleau-Ponty, exigindo um descentramento ainda mais radical da subjetividade? Eis algumas perguntas que permanecem sem resposta. De qualquer modo, se essas questões ainda nos instigam, isso significa que pensamos depois de Merleau-Ponty, e que sua obra ainda pode engendrar frutos para além da pós-humanidade.

1 R. Barbaras. L'être du phénomène. Sur l'ontologie de Merleau-Ponty. Paris: Millon, 1991 e R. Barbaras. Le tournant de l'expérience. Recherches sur la philosophie de Merleau-Ponty Paris:Vrin, 1998. Deve-se observar que Barbaras - em suas atuais investigações sobre o conceito de vida, as quais delineiam uma perspectiva filosófica original -, é hoje um dos principais continuadores do projeto filosófico de Merleau-Ponty.

2 No ensaio "O Filósofo e sua Sombra", encontramos uma análise da tradição husserliana, a qual torna explícito o tipo de relação que o pensamento atual pode entreter com o passado: “Assim como o mundo percebido só subsiste mediante os reflexos, as sombras, os níveis, os horizontes entre as coisas (...) - também a obra e o pensamento de um filósofo são feitos igualmente de certas articulações entre as coisas ditas, a cujo respeito não há dilema entre a interpretação objetiva e o arbitrário, já que aí não se trata de objetos de pensamento, já que, como a sombra e o reflexo, seriam destruídos se fossem submetidos à observação analítica ou ao pensamento isolante, e apenas podemos ser-lhes fiéis e reencontrá-los pensando-os outra vez" (M. Merleau-Ponty. Signos. Paris: Gallimard, 1960, p. 202).

3 Esse pensamento, segundo Foucault, nasce no fim do século XVIII, em conformidade com o surgimento das ciências humanas, e é sistematizado ao longo dos séculos XIX e XX, especialmente sob a chave da fenomenologia.

4 Trata-se do famoso artigo J. Derrida. "Cogito et histoire de la folie". In: L'écriture et la différence. Paris: Seuil, 1967, pp. 51-97, onde o filósofo - mediante uma crítica à Histoire de la folie à l'âge classique, de Foucault - reflete sobre a natureza do racional em nós, defendendo seu caráter originalmente hiperbólico e, portanto, excessivo. 